\title{
The effect of L-rhamnose on gastrointestinal transit rates, short chain fatty acids and appetite regulation
}

\author{
C.S. Byrne ${ }^{1}$, T. Preston ${ }^{2}$, J. Brignardello ${ }^{3}$, I. Garcia-Perez ${ }^{3}$, E. Holmes ${ }^{3}$, G.S. Frost ${ }^{1}$ and \\ D.J. Morrison ${ }^{2}$ \\ ${ }^{1}$ Nutrition and Dietetic Research Group, Division of Diabetes, Endocrinology and Metabolism, Faculty of Medicine, \\ Imperial College London, Hammersmith Campus, London, W12 0NN, ${ }^{2}$ Stable Isotope Biochemistry Laboratory, \\ Scottish Universities Environmental Research Centre, University of Glasgow, East Kilbride, G75 0QF and ${ }^{3}$ Department \\ of Surgery and Cancer, Computational and Systems Medicine, Imperial College London, South Kensington Campus, \\ London, SW7 $2 A Z$.
}

It has been hypothesised that the appetite-suppressing effects associated with the consumption of non-digestible carbohydrates (NDC) could be attributed to their effect on intestinal transit rates as well as the production of short chain fatty acids (SCFA) following their microbial fermentation ${ }^{(1)}$. An acute elevation in colonic production of the SCFA propionate has previously been shown to reduce ad libitum energy intake and to increase plasma concentrations of the anorexigenic gut hormones glucagon-like peptide-1 (GLP-1) and peptide YY (PYY) in humans acutely ${ }^{(2)}$. The aim of conducting this pilot study was to determine the effects of the consumption of L-rhamnose, a reportedly propionate-producing compound ${ }^{(3)}$, on gut transit times. We hypothesised that L-rhamnose would increase plasma propionate leading to a reduction in appetite, independent of changes in gastrointestinal transit times.

We used a dual ${ }^{13} \mathrm{C}$ octanoic acid/lactose ${ }^{13} \mathrm{C}$-ureide breath test to measure intestinal transit times following the consumption of $25 \mathrm{~g} / \mathrm{d}$ L-rhamnose, compared with inulin and cellulose, in ten healthy humans in a randomised cross-over design. In addition, breath $\mathrm{H}_{2}$ measurements, which are routinely used as a marker of colonic fermentation ${ }^{(4)}$, were collected. Gastric emptying (GE) and orocaecal transit times (OCTT) were derived from the breath ${ }^{13} \mathrm{C}$ data and compared with breath $\mathrm{H}_{2}$ excretion times. In addition, plasma SCFA and PYY concentrations were measured and visual analogue scales were completed by participants. Areas under the curve (AUC) were calculated using the trapezoidal rule. Data were compared between groups using one-way ANOVA.

Based on the ${ }^{13} \mathrm{C}$ data, L-rhamnose significantly slowed GE rates compared to cellulose (effect size: mean $\pm \mathrm{SEM} ; 0.35 \pm 0.13 \mathrm{~h}$, $\mathrm{P}=0.023)$ and inulin $(0.30 \pm 0.11 \mathrm{~h}, \mathrm{P}=0.023)$ but there was no difference in OCTT between treatments $(\mathrm{P}=0.21)$. OCTT measured from breath ${ }^{13} \mathrm{C}$ data was highly correlated with breath $\mathrm{H}_{2}$ for inulin $\left(\mathrm{r}^{2}=0.89, \mathrm{P}<0.001\right)$ but not for L-rhamnose or cellulose $(\mathrm{P}=0.63-0.77)$. The breath $\mathrm{H}_{2}$ data suggested fermentation of L-rhamnose occurred before it reached the caecum. L-rhamnose consumption significantly increased the $\mathrm{AUC}_{0-480}$ for plasma propionate versus cellulose (effect size: $1.36 \pm 0.15 \mu \mathrm{M} \times \mathrm{min}, \mathrm{P}<0.001$ ) and inulin (effect size: $1.41 \pm 0.13 \mu \mathrm{M} \times \mathrm{min}, \mathrm{P}<0.001$ ) as well as the $\mathrm{AUC}_{0-480}$ for plasma PYY versus cellulose (effect size: $9.77 \pm 4.0 \mathrm{pmol} / \mathrm{L} x \mathrm{~min}, \mathrm{P}=0.037$ ) and inulin (effect size: $16.41 \pm 4.16 \mathrm{pmol} / \mathrm{L} \mathrm{x} \mathrm{min}, \mathrm{P}=0.003$ ). There was no difference in subjective appetite measures between groups $(\mathrm{P}=0.37)$.

In conclusion, the NDCs tested had a minimal effect on intestinal transit time. Our data suggest that L-rhamnose is partially fermented in the small intestine, despite L-rhamnose previously being considered to reach the colon intact, and that breath $\mathrm{H}_{2}$ reflects the site of gastrointestinal fermentation and is only a reliable marker of OCTT for certain NDCs (e.g. inulin). Future studies should focus on investigating the appetite-suppressing potential of L-rhamnose.

1. Slavin JL. (2005) Nutrition 21(3), 411-8.

2. Chambers ES, Viardot A, Psichas A, et al. (2014) Gut. 64, 1744-54.

3. Vogt JA, Pencharz PB \& Wolever TM. (2004) Am J Clin Nutr. 80(1), 89-94.

4. Morrison D, Dodson B, Preston T \& Weaver L. (2003) Eur J Clin Nutr. 57(8), 1017-24. 